\title{
Adoption of Six Sigma's DMAIC to Reduce Complications in IntraLase Surgeries
}

\author{
İbrahim Şahbaz ${ }^{1}$, Mehmet Tolga Taner, ${ }^{2,}$, Mustafa Eliaçık ${ }^{3}$, Gamze Kağan ${ }^{4}$ and \\ Engin Erbaş ${ }^{5}$
}

${ }^{1}$ Department of Opticianry, Uskudar University, Istanbul, Turkey

${ }^{2}$ Department of Healthcare Management, Uskudar University, Istanbul, Turkey

${ }^{3}$ Department of Ophthalmology, Medipol University, Istanbul, Turkey

${ }^{4}$ Department of Occupational Health and Safety, Uskudar University, Istanbul, Turkey

${ }^{5}$ Institute of Health Sciences, Department of Hospital Administration, Uskudar University, Istanbul, Turkey

Abstract: Purpose: To show how a private eye care center in Turkey initiated Six Sigma principles to reduce the number of complications encountered during and after femtosecond laser-assisted LASIK (IntraLase) surgeries.

Method: Data were collected for five years. To analyse the complications among 448 surgeries, main tools of Six Sigma's Define-Measure-Analyze-Improve-Control (DMAIC) improvement cycle such as SIPOC table, Fishbone Diagram and, Failure, Mode and Effect Analysis were implemented. Sources and root causes of seventeen types of complications were identified and reported.

Results: For a successful IntraLase surgery, experience of the refractive surgeon, patient's anatomy and calibration of laser power were determined to be the "critical few" factors whereas, patient's psychology, sterilization and hygiene, and suction-ring's pressure were found to be the "trivial many" factors. The most frequently occurring complication was found to be subconjunctival haemorrhage.

Conclusion: The process sigma level of the process was measured to be 3.3547. The surgical team concluded that sixteen complications (out of seventeen) should be significantly reduced by taking the necessary preventive measures.

Keywords: Six Sigma, Ophthalmology, IntraLase Surgery, Complications.

\section{INTRODUCTION}

Laser in situ keratomileusis (LASIK) is currently the most popular and satisfactory refractive surgery procedure in the world. Solomao et al. [1] conducted a literature search for the years 1988 to 2008 and reported that the patient satisfaction rate after myopic LASIK was $95.3 \%$, and after hyperopic LASIK was $96.3 \%$.

The critical step of LASIK surgery is the creation of the corneal flap [2]. The two most common ways to create the flap are with a femtosecond (FS) laser or mechanical microkeratome, both of which have different mechanisms of action to create corneal resections [3]. The safety of mechanical microkeratomes has improved remarkably over the years but complications still occur, especially in patients with thin, flat or steep corneas [2]. In addition, the mechanical nature of the cut can be unappealing for the patient. Preparation of the corneal flap with a FS laser appears to overcome these problems [4]. Thus, in

*Address correspondence to this author at the Department of Healthcare Management, Uskudar University, Istanbul, Turkey; Tel: 00-90-216-400-2222;

Fax: 00-90-216-4741256; E-mail: mehmettolga.taner@uskudar.edu.tr recent years, FS laser flap creation is rapidly gaining popularity because both surgeons and patients realize the increased accuracy and safety of these instruments over mechanical microkeratomes [5]. By 2010, over $50 \%$ of the LASIK procedures in the United States were performed with the FS laser [6].

The FS laser represents a significant progress in the field of refractive surgery [6]. The list of its applications is expanding and the benefits in terms of improved safety and efficacy is making the FS technology the gold standard in some surgical techniques [7]. Moreover, since the introduction of the FS laser and its approval by the FDA for patient use in 2001, several technological advances have been implemented, have reduced flap creation times and allowed for reduced energy levels [6].

Compared to mechanical microkeratomes, FS lasers create flaps with exact size, shape and depth, with more predictable, desirable planar configuration and uniform thickness [8]. They are also capable of creating more predictable, more vertical and desirable side-cut profiles and allow the surgeon to specify the side-cut angle [6]. 
Refractive surgeons need to be aware of the types of complications that can occur, how to refrain from them and how to manage them to ensure the best possible outcomes. Many of the complications such as buttonhole or freecaps, anterior chamber penetration, flap displacement and epithelial ingrowth are reported to have been eliminated or reduced to lower levels by the use of the FS laser [6]. However, an increase in Diffuse Lamellar Keratitis and other entities such as Transient Light Sensitivity Syndrome and rainbow glare have been described [6]. Possible other complications occuring during or after the IntraLase surgery were given to be iatrogenic keratectasia, flap tears, irregular astigmatism, flap wrinkling, transient light sensitivity syndrome, anterior chamber bubble formation, vertical gas breakthrough, the opaque bubble layer, dry eye and rainbow glare [9-11].

Haft et al. [12] reported that less than $0.92 \%$ of the eyes in his study had direct and indirect complications due to FS flap creation and added that $0.42 \%$ of the eyes had developed DLK; $0.25 \%$ had had TLSS; $0.17 \%$ had had premature gas breaktrough; $0.06 \%$ had had incomplete flaps due to suction loss; and $0.02 \%$ had had irregular flap due to previous corneal scar. In another study by Davison and Johnson [13], in the 3009 consecutive IntraLaser surgeries from August 2002 through July 2009, eleven (0.37\%) intraoperative complications occurred. Eight of these were suction breaks; one of them was incomplete flap; two cases of adherent flap were reported to be adherent flap.

The FS lasers have a particular range of adjustable parameters that can be controlled by the refractive surgeon. However, as with any surgical procedure, there is a learning curve associated with using the FS laser. Thus, a thorough understanding of the common parameters and their impact on flap creation is necessary for a surgeon to optimize the FS laser settings. The important parameters are flap thickness, bed energy, flap diameter, spot size and separation, pocket profile, side cut angle/energy, and hinge location. As the refractive surgeon gains more interoperative experience, fine-tuning adjustments can be made with various parameters to minimize side effects and facilitate flap creation [6].

The use of Six Sigma, as a quality improvement method, can improve the surgical safety, efficiency and accuracy of many ophthalmic surgeries [14]. Originally initiated by Motorola, Honeywell and General Electric [15], Six Sigma is a powerful performance improvement tool that is changing the face of modern healthcare delivery today [16]. Although it was initially introduced for the manufacturing processes, it is being implemented in diagnostic imaging processes [17], emergency room [18], paramedic backup [19], laboratory [20], cataract surgery [14], radiology [21], surgical site infections [22], microkeratome assisted LASIK surgery [23], strabismus surgery [24] and stent insertion [25] as a cost-effective way to improve quality, performance and productivity [16].

A Six Sigma process produces 3.4 defective parts per million opportunities (DPMO) [26]. As a method to eliminate errors, Six Sigma uses a structured methodology called DMAIC to find the main causes behind problems and to reach near perfect processes. DMAIC is useful to analyze and modify complicated time-sensitive healthcare processes involving multiple specialists and treatment areas by identifying and removing root causes of errors or complications and thus minimizing healthcare process variability [16].

In this study, a Six Sigma infrastructure was developed for a private Turkish eye center in order to improve the outcomes of their IntraLase surgery process. In addition, sigma level of each type of complication are calculated and reported.

\section{ANALYSIS}

\section{Application of Six Sigma's DMAIC for IntraLase Surgery}

DMAIC is a data-driven quality strategy for improving healthcare processes, and is an integral part of the healthcare institution's Six Sigma Quality Initiative [16]. It is an acronym for five interconnected phases: Define, Measure, Analyze, Improve, and Control [16]. Each step in the cyclical DMAIC Process is required to ensure the best possible results. First, the problem, objectives, core process and Critical-toQuality issues are defined. Next, the data are collected to measure the defect rate. Then, they are analyzed and root causes of defects and opportunities for improvement are determined. Following this, the current process is improved by designing a new process to fix and prevent problems. An implementation plan is developed and deployed. Finally, the improvements to keep the process on the new course are continuously monitored, controlled and institutionalized.

The eye care center decided that Six Sigma was the best way to achieve their goals. A surgical team was assembled and trained in the methodology. Committed 
and consistent leadership to overcome the complications was assured by this team. The surgical team firstly generated a SIPOC (Supplier, Input, Process, Output and Customer) Table for IntraLase surgery process (Table 1).

The surgical team defined the performance objective as patients with corrected refractive error after nearly perfect IntraLase procedures; or as patients with "Emmetropia" after perfect IntraLase procedure, i.e. no refractive error. They also defined a complication as any unwanted outcome inhibiting the patient to be cured and stable. It compounds the illness and decreases the patient's quality of life or prolongs the planned hospital stay [25]. To achieve the performance objective, the surgical team first determined CTQ factors by brainstorming. The CTQ factors were those factors that might have had an influence on the objective.

The surgical team determined the metrics to measure existing process. The metrics chosen for the Six Sigma study were:

1. Total number of IntraLase surgeries performed in the eye care center,
2. Number of complications.

Data were collected for a period of 5-years. In this period, IntraLase surgeries were performed on 448 eyes. Complications had been noted as they occurred. The surgical team identified seventeen types of complications and classified them as how soon they occur, i.e. acute and/or sub-acute (Table 2). Sources (Table 3) and root-causes (Table 4) of these complications are tabulated by type.

The incidence of complications depends on multiple sources (variables). Measurement variables, surgeon variables, staff variables, patient variables, suction-ring variables, and laser variables were all evaluated to assess the root-cause of a complication (Tables 3 and 4).

The surgical team analysed the occurrence frequency of each complication (Table 4) and related them with the root-causes on Table 4 . The analysis revealed that Type I, II and III were the three most frequently occurring complications in the IntraLase surgeries (Table 4). Then, they classified the CTQs as "vital few factors" and "trivial many factors" according to how frequent they caused the complications. The "vital

Table 1: SIPOC Table for IntraLase Surgery

\begin{tabular}{|c|c|c|c|c|}
\hline SUPPLIER & INPUT & PROCESS & OUTPUT & CUSTOMER \\
\hline $\begin{array}{l}\text { Refractive } \\
\text { surgeon }\end{array}$ & Patient & $\begin{array}{l}\text { Ocular examination (i.e. acuity testing, refraction, computerized } \\
\text { videokeratography, wave front analysis if available, slit-lamp } \\
\text { examination, retinal evaluation, eye dominance testing, and } \\
\text { evaluation for monovision when appropriate), } \\
\text { Measurement of pupil size, } \\
\text { Schirmer test }\end{array}$ & Emmetropia & Patient \\
\hline $\begin{array}{l}\text { Biomedical } \\
\text { technician }\end{array}$ & Laser & $\begin{array}{c}\text { Biometric measurements, } \\
\text { Corneal topography. }\end{array}$ & $\begin{array}{c}\text { Corrected } \\
\text { refractive error }\end{array}$ & \\
\hline Nurse & Microscope & Evaluation by refractive surgeon & & \\
\hline \multirow[t]{2}{*}{$\begin{array}{l}\text { Laser } \\
\text { technician }\end{array}$} & $\begin{array}{c}\text { Joystick, Display } \\
\text { panel, Keyboard, } \\
\text { Laser console, Laser } \\
\text { aperture and loading } \\
\text { deck, } \\
\text { Beam delivery } \\
\text { device, } \\
\text { Control panel, } \\
\text { Articulated arm, } \\
\text { Pre-sterilized single- } \\
\text { use, disposable } \\
\text { applanation cones, } \\
\text { Suction rings Syringe }\end{array}$ & $\begin{array}{c}\text { Room setup, } \\
\text { Laser setup, } \\
\text { Procedure programming (depth, size, hinge), } \\
\text { Patient preparation, } \\
\text { Head positioning, } \\
\text { Center or Offset treatment, } \\
\text { Suction Ring Assembly, } \\
\text { Applanation, } \\
\text { Edge release, } \\
\text { Lifting of the flap, } \\
\text { Ablation, } \\
\text { Repositioning of the flap, } \\
\text { Irrigation. }\end{array}$ & & \\
\hline & & Discharge & & \\
\hline
\end{tabular}


Table 2: Complications Experienced (May 2008 - December 2013)

\begin{tabular}{|c|c|c|c|c|c|}
\hline Type I & Subconjunctival haemorrhage & $x$ & $x$ & $x$ & \\
\hline Type III & Punctate Epitheliopathy & & $\mathrm{X}$ & $\mathrm{X}$ & \\
\hline Type IV & Overcorrection & & $\mathrm{X}$ & $\mathrm{X}$ & $x$ \\
\hline Type VI & Undercorrection & & $x$ & $\mathrm{X}$ & $\mathrm{X}$ \\
\hline Type VII & Chemosis & & $\mathrm{x}$ & $\mathrm{x}$ & \\
\hline Type VIII & Sidecut inefficiency (use of scissors) & $x$ & & $\mathrm{X}$ & \\
\hline Type IX & $\begin{array}{l}\text { Sidecut inefficiency } \\
\text { (use of syringe) }\end{array}$ & $x$ & & $x$ & \\
\hline Type XII & Dry eye & & & $\mathrm{X}$ & $x$ \\
\hline Type XIII & Diffuse Lamellar Keratitis & & $x$ & $x$ & \\
\hline Type XIV & Decenteralised flap & $x$ & & $x$ & \\
\hline Type XV & Suction loss & $x$ & & $x$ & \\
\hline Type XVI & Interface debris & $\mathrm{X}$ & & $\mathrm{X}$ & \\
\hline Type XVII & Tear in flap & $x$ & & $x$ & \\
\hline
\end{tabular}

Table 3: Sources of Complications

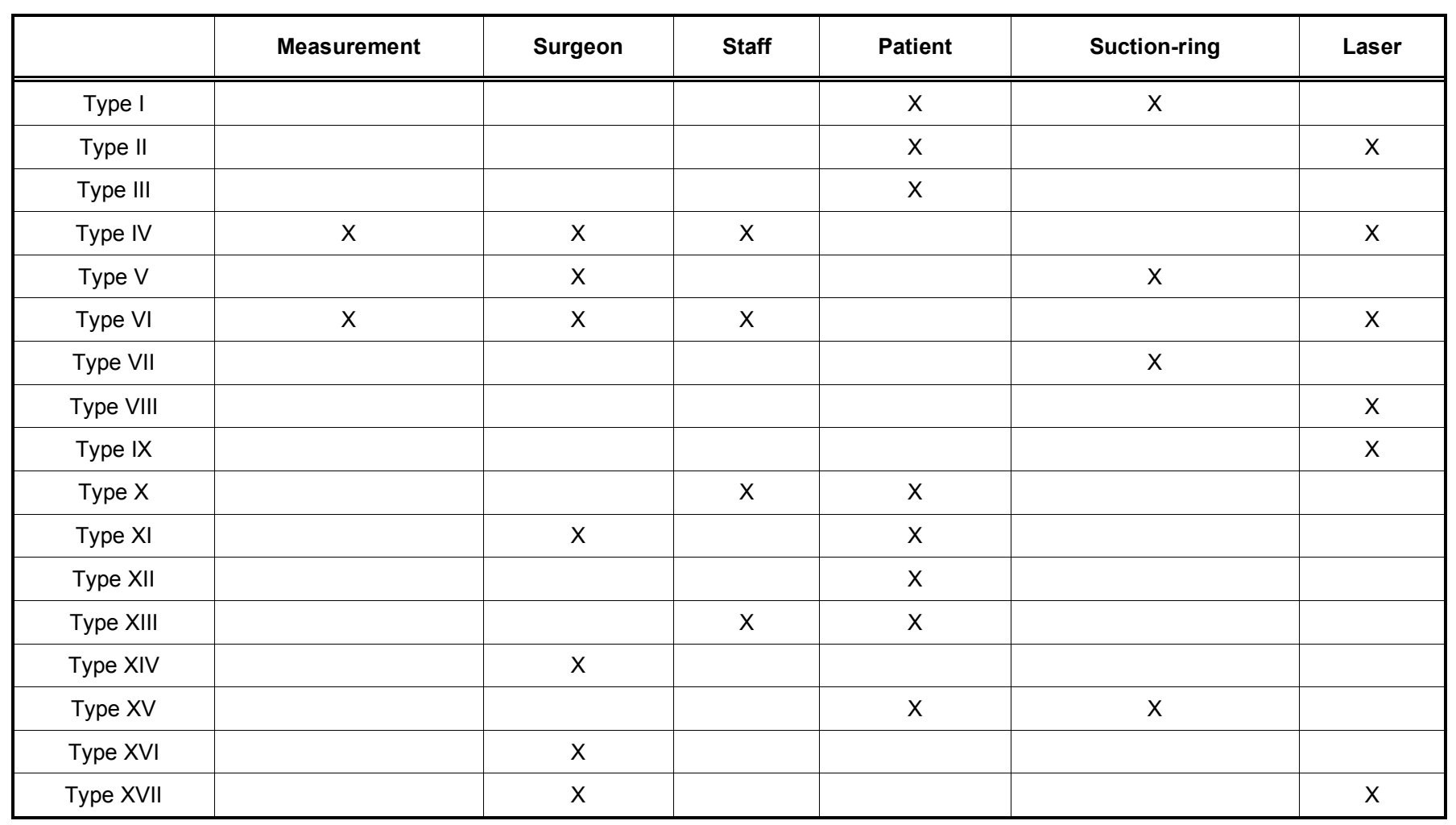


Table 4: Root-Causes of Complications

\begin{tabular}{|c|c|c|c|c|c|c|}
\hline & Experience & $\begin{array}{l}\text { Calibration } \\
\text { (Laser Power) }\end{array}$ & $\begin{array}{c}\text { Sterilization } \\
\text { And } \\
\text { Hygiene }\end{array}$ & $\begin{array}{l}\text { Patient's } \\
\text { Anatomy }\end{array}$ & $\begin{array}{c}\text { Patient's } \\
\text { Psychology }\end{array}$ & $\begin{array}{l}\text { Suction } \\
\text { Ring's } \\
\text { Pressure }\end{array}$ \\
\hline Type II & $x$ & & & $x$ & & \\
\hline Type III & & & & $x$ & & \\
\hline Type V & & $x$ & & & & \\
\hline Type VI & $x$ & $x$ & & & & \\
\hline Type VII & & & & $x$ & & $x$ \\
\hline Type VIII & & $x$ & & & & \\
\hline Type XII & & & & $x$ & & \\
\hline Type XIII & $x$ & & $x$ & $x$ & & \\
\hline Type XIV & $x$ & & & & & \\
\hline Type XV & $x$ & & & $x$ & $x$ & \\
\hline Type XVI & $x$ & & & & & \\
\hline Type XVII & $x$ & $x$ & & & & \\
\hline
\end{tabular}

few" factors, i.e. the factors that had the most impact on the success of IntraLase surgery were determined to be the experience of the refractive surgeon, patient's anatomy and calibration of laser power. The other factors, i.e. patient's psychology, sterilization and hygiene, and suction-ring's pressure were the "trivial many".

\section{DISCUSSION}

To measure the current sigma level of a complication, surgical team calculated the current Defects per One Million Opportunities (DPMO) and sigma levels for each complication type (Table 5). For this, two distinct datasets are required:

$A=$ Total number of IntraLase surgeries performed.

$\mathrm{B}=$ Total number of complications occurred.

The DPMO formula is:

$D P M O=B \times 1,000,000 / A$

Normal distribution underlies Six Sigma's statistical assumptions [14]. An empirically-based 1.5 sigma shift is introduced into the calculation [14]. A higher sigma level indicates a lower rate of complications and a more efficient process [25].

The highest sigma level was obtained for Type XVII. The lowest sigma level was found to be belong to Type I. Taner et al. [25], determined a sigma level of 4.00 as the cut-off for being a complication to be significantly reduced.

The surgical team also calculated the process sigma level as the arithmetic average of seventeen complications and found to be 3.3547 .

Risk assessment of the IntraLase surgery was achieved by the failure mode and effect analysis (FMEA). Utilization of the FMEA involved break down the process into individual steps: potential failure modes (i.e. complications), severity score, probability score, hazard score, criticality and detection, so that the surgery team could look at key drivers in the process based on the past experience.

Complication trends and their consequences over a five-year period had been monitored and recorded. Surgical team prioritized the complications according to how serious their consequences were (i.e. severity 
Table 5: Cumulative Frequency, DPMO and Sigma Levels

\begin{tabular}{|c|c|c|c|c|}
\hline & Count & Frequency (\%) & DPMO & Sigma Level \\
\hline Type I & 358 & 79.91 & 799107 & 0.66 \\
\hline Type II & 62 & 13.83 & 138393 & 2.59 \\
\hline Type III & 44 & 9.82 & 98214 & 2.79 \\
\hline Type IV & 16 & 3.57 & 35714 & 3.30 \\
\hline Type V & 12 & 2.67 & 26786 & 3.43 \\
\hline Type VI & 12 & 2.67 & 26786 & 3.43 \\
\hline Type VII & 12 & 2.67 & 26786 & 3.43 \\
\hline Type VIII & 10 & 2.23 & 22321 & 3.51 \\
\hline Type IX & 9 & 2.00 & 20089 & 3.55 \\
\hline Type X & 8 & 1.78 & 17857 & 3.60 \\
\hline Type XI & 8 & 1.78 & 17857 & 3.60 \\
\hline Type XII & 8 & 1.78 & 17857 & 3.60 \\
\hline Type XIII & 7 & 1.56 & 15625 & 3.65 \\
\hline Type XIV & 6 & 1.33 & 13393 & 3.71 \\
\hline Type XV & 4 & 0.89 & 8929 & 3.87 \\
\hline Type XVI & 3 & 0.66 & 6696 & 3.97 \\
\hline Type XVII & 1 & 0.22 & 2232 & 4.34 \\
\hline
\end{tabular}

score), how frequently they occurred (i.e. probability score) and how easily they could be detected. Hazard analysis was employed in order to identify failure modes and their causes and effects. The surgery team determined the severity of each complication and assigned scores for them. The severity of each complication was scored from 1 to 4 (Table 6 ).

For each complication type, the hazard score was calculated by multiplying the severity score with the probability score. Consequently, an FMEA table was drawn (Table 7). Being not an important complication individually for any patient but the most frequently occuring one by far, Type I yielded the highest hazard score. Type $\mathrm{V}$ and $\mathrm{VI}$ were equally hazardous complications and so were Type $X$ and XII. According to FMEA, Type XVII was the least hazardous complication.

The surgical team developed preventive measures for each type of complication in order to bring the overall IntraLase process under control. They also noted that there had still been limited progress in understanding the basic mechanisms underlying the complications such as Type $X$ and XIII. Nonetheless, they implemented the following corrective action plan to reduce and/or eliminate other complications.

It is underlined that proper laser room environment is critical for the surgical success of IntraLase and that it required proper cleaning, assembly and accurate calibration and setup of the laser. Appropriate humidity, temperature, and air purification must be present in the laser room at all times. Proper and periodic maintenance of the FS laser by the technician is also an obligation.

It is suggested that complications related directly to the FS laser are largely preventable if the laser is working properly and its beam centration, fluence and beam quality are evaluated critically prior to surgery. Energy fulence and beam quality of the FS laser must be routinely calibrated and evaluated.

Since intraocular pressure is increased during the IntraLase surgery, it is suggested that care must be taken to minimize fixation and applanation times and that incomplete applanation may result in thin or nonuniform flap thickness.

Table 6: Severity Scores

\begin{tabular}{|c|c|c|c|c|}
\hline Severity Score & $\mathbf{4}$ & $\mathbf{3}$ & $\mathbf{2}$ & $\mathbf{1}$ \\
\hline \hline Severity of Complication & Permanent harm & Temporary harm & Bias & No harm \\
\hline
\end{tabular}


Table 7: FMEA Table

\begin{tabular}{|c|c|c|c|c|c|}
\hline \multirow[t]{2}{*}{ Complication Type } & \multicolumn{3}{|c|}{ Hazard Analysis } & \multicolumn{2}{|c|}{ Decision Tree Analysis } \\
\hline & $\begin{array}{l}\text { Severity } \\
\text { Score }\end{array}$ & $\begin{array}{c}\text { Probability } \\
\text { Score }\end{array}$ & $\begin{array}{c}\text { Hazard } \\
\text { Score }\end{array}$ & Critical? & Detectable? \\
\hline Type I & 1 & 0.7991 & 0.7991 & No & Yes \\
\hline Type II & 3 & 0.1383 & 0.4149 & Yes & Yes \\
\hline Type III & 2 & 0.0982 & 0.1964 & No & Yes \\
\hline Type IV & 4 & 0.0357 & 0.1428 & Yes & Yes \\
\hline Type V & 4 & 0.0267 & 0.1068 & Yes & Yes \\
\hline Type VI & 4 & 0.0267 & 0.1068 & Yes & Yes \\
\hline Type VII & 1 & 0.0267 & 0.0267 & No & Yes \\
\hline Type VIII & 3 & 0.0223 & 0.0669 & Yes & Yes \\
\hline Type IX & 3 & 0.0200 & 0.0600 & Yes & Yes \\
\hline Type X & 3 & 0.0178 & 0.0534 & Yes & No \\
\hline Type XI & 4 & 0.0178 & 0.0712 & Yes & Yes \\
\hline Type XII & 3 & 0.0178 & 0.0534 & Yes & Yes \\
\hline Type XIII & 4 & 0.0156 & 0.0624 & Yes & No \\
\hline Type XIV & 2 & 0.0133 & 0.0266 & Yes & Yes \\
\hline Type XV & 2 & 0.0089 & 0.0178 & Yes & Yes \\
\hline Type XVI & 2 & 0.0066 & 0.0132 & No & Yes \\
\hline Type XVII & 4 & 0.0022 & 0.0088 & Yes & Yes \\
\hline
\end{tabular}

The surgical team determined that incomplete flaps occured due to the contaminated or damaged applanation cone and suggested its replacement.

It is proposed that prior to surgery, refractive surgeons give information to patients on the risks of the laser and overall surgery. In addition, the refractive surgeon counsels patients to be co-operative during the surgery. To avoid blefarospasm, patients are asked to relax during the surgery.

The need to appropriately train the refractive surgeons on the use of the FS laser, adequate use of suction-ring and proper cleaning of cornea to avoid contamination in the lamellar interface is also discussed.

\section{RESULTS}

FS laser is the latest innovation in the field of ophthalmology with a great future. With its everexpanding repertoire of uses, it will soon be used in almost every aspect of ophthalmic science. It is expected to completely revolutionize the minimally invasive ophthalmic surgery and offer new possibilities in the field of refractive surgery in next five years with wider range of applications.

Thus, the effectiveness and safety of the FS laser use in LASIK to correct refractive errors are important issues. In this study, authors show that seventeen types of complications are encountered in the eye care center while performing IntraLase surgeries. The analysis showed that the IntraLase complications in the eye care centre had equally occurred both intraoperatively and postoperatively. Postoperative complications were almost always related to events that had occurred during surgery.

It is found that refractive surgeons are in a key position to eliminate the complications. Their experience is of utmost importance. Many complications were related to the learning curve associated with FS laser use. These complication rates were reduced as refractive surgeons gained experience and was trained on how to identify, minimize or eliminate the sources and root-causes of the complications.

The process sigma level of the overall process (i.e. IntraLase surgeries made in 5-years) was measured to be 3.3547 . Sixteen of the more frequently occuring complications need to be significantly reduced by taking the necessary preventative measures.

\section{REFERENCES}

[1] Salomao MQ, Wilson SE. Femtosecond laser in laser in situ keratomileusis. J Cataract Refract Surg 2010; 36(6): 102432.

http://dx.doi.org/10.1016/j.jcrs.2010.03.025 
[2] Kezirian GM, Stonecipher KG. Comparison of the IntraLase femtosecond laser and mechanical keratomes for laser in situ keratomileusis. J Cataract Refract Surg 2004; 30: 804-11. http://dx.doi.org/10.1016/j.jcrs.2003.10.026

[3] Patel SV, Maguire LJ, McLaren JW, Hodge DO, Bourne WM. Femtosecond laser versus mechanical microkeratomefor LASIK: A randomized controlled study. Ophthalmol 2007; 114(8): 1482-90. http://dx.doi.org/10.1016/j.ophtha.2006.10.057

[4] Vayr F, Chastang P, Hoang-Xuan T. Laser and mechanical microkeratomes. Refractive Surgery (Azar DT), $2^{\text {nd }}$ ed. Mosby Elsevier, China 2007; pp. 147-155.

[5] Montes-Mico R, Rodriguez-Galietero A, Alio JL. Femtosecond laser versus mechanical keratome LASIK for myopia. Ophthalmol 2007; 114(1): 62-8. http://dx.doi.org/10.1016/j.ophtha.2006.07.019

[6] Bryar PJ, Hardten DR, Rosenfeld SI. Femtosecond laser flap creation. in the LASIK handbook: A Case-Based Approach. (Feder RS, Ed.), Lippincott Williams and Wilkins Publishers: $2^{\text {nd }}$ ed. 2013; pp. 55-65.

[7] Wevill M. The benefits of femtosecond laser applications in Femtosecond laser techniques and technology. (Garg A, Alio JL, Eds.); Jaypee Brothers Medical Publishers Inc.: 2012; pp. 19-23. http://dx.doi.org/10.5005/jp/books/11632 3

[8] Tanna M, Schallhorn SC, Hettinger KA. Femtosecond laser versus mechanical microkeratome: $A$ retrospective comparison of visual outcomes at 3 months. J Refract Surg 2009; 25(7): S668-71.

[9] Stonecipher K, Ignacio TS, Stonecipher K. Advances in refractive surgery: Microkeratome and femtosecond laser flap creation in relation to safety, efficacy, predictability and biomechanical stability. Curr Opin Ophthalmol 2006; 17(4): 368-72. http://dx.doi.org/10.1097/01.icu.0000233957.88509.2d

[10] Kılıç A. Femtosecond laser flap complications. in Femtosecond laser techniques and technology. (Garg A, Alio JL, Eds.); Jaypee Brothers Medical Publishers Inc.: 2012; pp. 130-7. http://dx.doi.org/10.5005/jp/books/11632 17

[11] Chang JSM. Femtosecond laser complications and their management. Cataract and Refractive Surgery Today 2010; June.

[12] Haft P, Yoo SH, Kymionis GD, Ide T, O'Brien TP, Culbertson WW. Complications of LASIK flaps made by the IntraLase 15- and $30 \mathrm{kHz}$ femtosecondlasers. J Refract Surg 2009; 25(11): 979-84.

http://dx.doi.org/10.3928/1081597X-20091016-02
[13] Davison JA, Johnson SC. Intraoperative complications of LASIK flaps using the IntraLase femtosecond laser in 3009 cases. J Refract Surg 2010; 26(11): 851-7. http://dx.doi.org/10.3928/1081597X-20100114-07

[14] Taner MT. Application of Six Sigma Methodology to a cataract surgery unit. IJHCQA 2013; 26(8): 768-85.

[15] Mehrjerdi YZ. Six Sigma: Methodology, tools and its future. Int J Assembly Automation 2011; 31(1): 79-88. http://dx.doi.org/10.1108/01445151111104209

[16] Taner MT, Sezen B, Antony J. An overview of Six Sigma applications in healthcare industry. IJHCQA 2007; 20(4): 329-40.

[17] Taner MT, Sezen B, Atwat KM. Application of Six Sigma Methodology to a Diagnostic Imaging Process. IJHCQA 2012; 25(4): 274-90.

[18] Miller MJ, Ferrin DM, Szymanski JM. Simulating Six Sigma improvement ideas for a hospital emergency department. Proceedings of the IEEE Winter Simulation Conference, New Orleans, December 7-10, 2003; 1926-9.

[19] Taner MT, Sezen B. An application of Six Sigma Methodology to turnover intentions in health care. IJHCQA 2009; 22(3): 252-65.

[20] Nevalainen D, Berte L, Kraft C, Leigh E, Picaso L, Morgan T. Evaluating laboratory performance on quality indicators with the Six Sigma scale. Archiv Pathol Lab Med 2000; 124(4): 516-9.

[21] Cherry J, Seshadri S. Six Sigma: Using statistics to reduce process variability and costs in radiology. Radiol Manag 2000; November/December: 42-5.

[22] Pexton C, Young D. Reducing surgical site infections through Six Sigma and change management. Patient Safety Quality Healthcare 2004; 1(1): 1-8.

[23] Taner MT, Kagan G, Sahbaz I, Erbas E, Kagan SB. A Preliminary study for Six Sigma implementation in Laser in situ Keratomileusis (LASIK) Surgeries. IRMM 2014; 4(1): 2433.

[24] Taner MT, Sahbaz I, Kagan G, Atwat K, Erbas E. Development of Six Sigma infrastructure for strabismus surgeries. IRMM 2014; 4(1): 49-58.

[25] Taner MT, Kagan G, Celik S, Erbas E, Kagan MK. Formation of Six Sigma infrastructure for the coronary stenting process. IRMM 2013; 3(4): 232-42.

[26] Buck C. Application of Six Sigma to reduce medical errors. Annual Quality Congress Proceedings, Charlotte, April 11-15 $2001 ; 739-42$.

Received on 30-01-2014

http://dx.doi.org/10.6000/1929-6029.2014.03.02.6

(c) 2014 Şahbaz et al.; Licensee Lifescience Global.

This is an open access article licensed under the terms of the Creative Commons Attribution Non-Commercial License (http://creativecommons.org/licenses/by-nc/3.0/) which permits unrestricted, non-commercial use, distribution and reproduction in any medium, provided the work is properly cited. 